\title{
Juan Montaño Escobar, el jazzman de Black Lives Matter, y su son de los 8 minutos 46 segundos
}

\author{
Juan Montaño Escobar, the Jazzman of Black Lives Matter, \\ and His 8 Minutes 46 Seconds Son
}

Michael Handelsman

University of Tennessee

Tennessee, Estados Unidos

Artículo de investigación

https://doi.org/10.32719/13900102.2021.49.7

Fecha de recepción: 8 de septiembre de 2020

Fecha de aceptación: 25 de octubre de 2020

Licencia Creative Commons

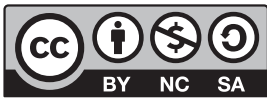




\section{RESUMEN}

En este ensayo se analiza la respuesta literaria de Juan Montaño Escobar del Ecuador al movimiento de Black Lives Matter y la trágica muerte de George F. Floyd, Jr. del 25 de mayo de 2020. Más que una protesta o denuncia, Montaño Escobar presenta una declaración de apropiación colectiva de esos 8 minutos 46 segundos robados para, así, retomarlos como un acto de (re)existencia y (re)significación precisamente porque Black Lives Matter y porque el movimiento trasciende su lugar y tiempo ya que resalta el racismo sistémico que define la historia de las Américas.

PalABRAS ClAVE: racismo, cimarronaje, diáspora, (re)existencia.

\section{ABSTRACT}

This essay analyses the Ecuadorian Juan Montaño Escobar's literary response to the Black Lives Movement and the tragic death of George F. Floyd, Jr. on May 25, 2020. More than a protest or denouncement, Montaño Escobar presents a declaration of collective appropriation of those 8 minutes 46 seconds in order to reclaim them as an act of (re)existence and (re) signification precisely because Black Lives Matter and because the movement transcends its time and place as it highlights the systemic racism that defines the history of the Americas. KEYWORDS: racism, maroonage, diaspora, (re)existence.

Mi dolor es grande.

- Manuel Zapata Olivella, Changó, el gran putas

It's not as simple as talkin' jive, just to stay alive.

—Nina Simone, "Revolution"

Black bodies swinging in the Southern breeze/ Strange fruit hanging from the poplar trees.

—Billie Holiday, "Strange Fruit"

TODA LA CREACIÓN artística de Juan Montaño Escobar (Ecuador; 1955), también conocido como el jazzman, junto con su pensamiento y activismo social, constituye un permanente reclamo por los 8 minutos 46 segundos que se le negaron a George Floyd, Jr. y a todos los demás George Floyds que atraviesan nuestra complicada historia dolorosamente secuestrada por su racismo sistémico. Para los propósitos de este ensayo, se entiende aquel reclamo no solo como una denuncia o protesta de un escritor/pensador/activista afrodescendiente, sino más bien como una de- 
claración de apropiación colectiva de esos 8 minutos 46 segundos robados para así retomarlos como un acto de (re)existencia y (re)significación precisamente de Black Lives Matter.

\section{SONES, SONEOS Y SONEROS \\ PARA LOS 8 MINUTOS 46 SEGUNDOS TODAVÍA POR RECUPERARSE}

No nos engañemos; aquellos ya icónicos 8 minutos 46 segundos del 25 de mayo de 2020 presenciados dolorosamente desde Minneapolis, Minnesota, no pertenecen solo a George Floyd, Jr., ni tampoco a esa fecha ni a esa ciudad. Es más, los últimos gritos ahogados de Floyd — "I can't breathe", "I can't breathe", "I can't breathe" — captan y sintetizan toda la historia de las Américas, comenzando con la llegada a estas orillas de aquellos barcos negreros en que los primeros esclavizados también gritaban "I can't breathe". Recordemos con Edouard Glissant que "Lo único escrito en los navíos con esclavos era el libro de cuentas con sus precios. Dentro del espacio de la nave, el llanto de los deportados se atoraba, como luego lo haría en las haciendas. Las reverberaciones de esta confrontación duran hasta hoy" $(1997,5){ }^{1}$

¿Quiénes hubieran adivinado que ese llanto atorado sería el primer soneo de un interminable son interpretado por un sinfín de soneros y soneras cuyos ritmos y melodías siguen trascendiendo los límites del tiempo y del espacio! Es así que la voz y la palabra de Juan Montaño Escobar vienen, pues, desde lejos y, si uno escucha con atención, se dará cuenta de que todo lo que el jazzman ha cantado y escrito no solo nace y se alimenta de ese primer soneo atorado, sino que también lo (re)significa, convirtiéndolo en un nuevo soneo del mismo son tan presente en los últimos respiros ahogados de George Floyd, Jr.

Desde sus primeros escritos publicados a lo largo de diez años en el diario Hoy de Quito y, luego, en El Telégrafo de Guayaquil, Juan Montaño se ha dedicado a reescribir aquel "libro de cuentas con sus precios", el mis-

1. Agradezco a Javier Pabón por haber compartido esta cita que se puede encontrar en su libro $A$ tres voces, que saldrá próximamente con el sello editorial de Abya-Yala de Quito, Ecuador. 
mo que Glissant denunció como primer atentado contra la existencia y la humanidad de los futuros muntus de las Américas. Se recordará que según la visión de Zapata Olivella en su Changó, el gran putas (1983), el muntu con su origen bantú "alude a la fuerza que une en un solo nudo al hombre con su ascendencia y descendencia inmerso en el universo presente, pasado y futuro" (514). En la novela, Zapata convoca a los muntus a luchar contra la desmemoria, aquella perversa estrategia colonial de deshumanización total, raíz misma del racismo sistémico que en 8 minutos 46 segundos borró a George Floyd, Jr., negándole por y para siempre su “ascendencia y descendencia" como ser humano.

Juan Montaño, el jazzman ecuatoriano, ha respondido incondicionalmente al llamado de Zapata para desarmar aquel libro de cuentas denunciado por Glissant, convirtiéndolo en un libro más bien de cuentos y de historias que, en su conjunto, consta como un vivo testimonio de existencia. En efecto, Montaño se ha entregado en cuerpo y alma a desenterrar la palabra secuestrada de aquellos primeros esclavizados para, así, dar voz a una memoria colectiva y ancestral, no como un mero acto arqueológico o filológico de curiosidades de un remoto pasado, sino como un acto de cimarronaje contemporáneo tan patente y palpitante en cualquier barrio de Mandela's Country, aquel compuesto ficticio suyo de barrios urbanos donde "el tam-tam parece no terminar nunca" y "todas las noches retumba el llamado de nuestros tambores" (Zapata Olivella 1983, 36-7). ${ }^{2}$

Los tambores - y las marimbas también- siempre han llenado los silencios de los ahogados originarios, y su interminable tam-tam resuena como un latido de corazón colectivo en toda la obra del jazzman. Para Montaño, su escritura es resistencia y, a la vez, (re)existencia ya que "La palabra, gráfica o fonética, tiene el poder de la persistencia en las existencias y así sostienen, en la memoria colectiva y cotidiana, la resistencia, para liberarnos de la no-existencia y volver, por siempre, a la re-existencia" (Montaño Escobar 2020a).

De ahí, la escritura sirve a Montaño como su tambor (o marimba) con el cual marca el paso de la historia hacia un futuro más justo, incluyente y plenamente suyo. Juan García Salazar enseñaba que "Para los mayo-

2. Para mayor información sobre Mandela's Country, véase mi Representaciones de lo afro y su recepción en Ecuador. Encuentros y desencuentros en tensión (Handelsman 2019, 202-14). 
res, la historia arranca en el momento en que empezamos a ser personas" y, como ha explicado Sonia Viveros: "Habíamos vivido muchos años con una crónica que no era nuestra y esa era la razón de nuestra despertenencia [...] entonces era necesario emprender el camino de volver a ser". ${ }^{3}$ Entre muchos afrodescendientes a lo ancho y a lo largo de la diáspora, se ha asumido ese volver a ser como un mandato ancestral. Por su parte, Juan Montaño también ha adoptado ese mandato como un firme compromiso porque como jazzman y cronista él sabe que permanentemente a través de la historia de las Américas, "los negros han afirmado la simple, pero radical, verdad de su propia humanidad y valor, y permanentemente América no los ha escuchado del todo" (Kaplan 2020; traducción mía). ${ }^{4}$

Es de notar que durante El Festival de Harlem de 1969, la inimitable Nina Simone cantó “Revolution", insistiendo que "It's not as simple as talkin' jive, just to stay alive". Las profundas y graves implicaciones de este verso permean los jam sessions de Montaño, especialmente en el que tituló “No puedo respirar": "I can’t breathe (no puedo respirar), salmodia definitiva de George Floyd. Esta súplica agónica debió repetirse por siglos en las sentinas de los barcos, en las plantaciones, en las minas o en las calles de las nacientes repúblicas americanas" $(2020 \mathrm{c}) .{ }^{5}$ De nuevo, otro soneo del mismo son que sigue negándose a ser ahogado.

La voz de George Floyd, Jr. con sus últimos gritos desesperados, sin embargo, no retumbaba sola al despertar a las multitudes del mundo entero de la perversa pesadilla del racismo sistémico; venía acompañada de un cuerpo angustiado, el mismo cuerpo presente en aquellos navíos negreros donde se escuchaban los primeros llantos atorados ya mencionados en líneas anteriores. La imagen que persiste de George Floyd, Jr. con esa rodilla en el cuello mientras él se ahogaba durante los 8 minutos 46 segundos nos recuerda que cada cuerpo tiene una voz y cada voz tiene un cuerpo, y cuerpo y voz sustentan una memoria colectiva que todavía lucha por escucharse y por verse. La investigadora Erika Sylva hace tiempo señaló que "el cuerpo no es solo físico, sino también simbólico" $(2010,228)$. Por su parte, el investigador Marcel Velázquez Castro ha comentado que el

3. Tanto la cita de Juan García como la de Viveros aparecen en Isabel Padilla y Juan Montaño $(2018,33)$.

4. Aunque Kaplan se refiere aquí a Estados Unidos, me parece igualmente pertinente al resto de América.

5. Montaño se refiere muy a menudo a sus escritos como jam sessions. 
“omnipotente control sobre el cuerpo del negro $[\ldots]$ se ve socavado $[\ldots]$ porque la memoria y la voz del negro serán sus armas [...]" de resistencia y existencia $(2012,12)$. De ahí la necesidad del poder oficial de defenderse mediante sus políticas y prácticas de invisibilización y silenciamiento.

Cuerpo, voz, memoria, resistencia, existencia: puro cimarronaje. ¿De qué otra manera hemos de entender “Ain’t I a Woman” de Sojouner Truth (1851) o aquel "I am a Man" (1968) del Movimiento de Derechos Civiles de los años 60 del siglo pasado? ¿Cómo escuchar a aquellas voces de "I am Somebody" de los años 70 y 80? "Black is Beautiful”, "Black Power" y, ahora, "Black Lives Matter"; de nuevo nos encontramos ante un tejido de historias que son muchas y una sola: cuerpo, voz, memoria, resistencia, existencia.

Cada una de esas frases deja una semilla para un renacer colectivo. Juan García Salazar comprendía ese renacer como un proceso permanente de sembrar para pensar y pensar para sembrar (García Salazar y Catherine Walsh, Pensar sembrando/sembrar pensando, 2017). Y cada siembra, cada pensamiento, conducía/conduce a una identidad de (re)existencia, la misma que Edizon León ha marcado como "la posibilidad de reinventar al sujeto luego de la fragmentación del Ser que significó la esclavitud, volver a pensar en la unidad del ser, romper con esa contradicción de ser y no ser, reconstruirse en un nuevo espacio y tiempo" $(2015,218)$.

Mientras León relaciona esa posibilidad de reinventar al Ser Negro con el cimarronaje, Stuart Hall la pondera como voz y cuerpo de una identidad arraigada en "aquellas experiencias históricas, aquellas tradiciones culturales, aquellos lenguajes perdidos y marginales, aquellas experiencias marginalizadas, aquellas personas e historias que aun permanecen sin ser escritas. Esas son las raíces específicas de la identidad” (2013, 429). Una identidad cimarrona, por cierto, ya que en todo momento, según nos recuerda Juan García, "la resistencia que los cimarrones/as construyeron desde los palenques territoriales, tiene que ser la inspiración para organizar el diálogo con los otros y para pensar en la defensa de nuestros derechos como pueblo" $(2020,96)$.

Así que la identidad de los afrodescendientes de las Américas es asumida como un proceso de resistencia permanente por existir, un proceso que Juan Montaño sitúa dentro de los 8 minutos 46 segundos permanentemente repetidos a través de toda la historia afro; y entre ahogos y gritos, entre aquel "I can't breathe" y "Black Lives Matter", Montaño pone en 
contexto este último soneo al explicar: "La sociedad dominante tiene en su inventario de poderes religión, educación, ejército e historia para construir y afinar sus privilegios raciales. Nuestra lucha es por la importancia consciente de existir. Así nos importamos, así nos merecemos" (2020d).

Aunque puede haber los que prefieran pensar que la tragedia de George Floyd, Jr. pertenece solo, o principalmente, a las condiciones raciales de Estados Unidos, Juan Montaño sabe y siente que aquellos $8 \mathrm{mi}$ nutos 46 segundos son suyos porque son de todos los afrodescendientes. Sin duda, el pensamiento de Montaño se ha alimentado de las palabras del Abuelo Zenón, quien enseñaba: "las comunidades de origen africano, somos un sola nación cultural, un solo pueblo, pues por encima de las fronteras, compartimos un mismo territorio, una misma sangre, una misma historia y por eso compartimos el mismo olvido por parte de los que ayer, nos separaron" (en Porras et al. 2012, 19). Si bien es cierto que esas palabras se referían en primera instancia a la Región Afro-Pacífica de Ecuador y Colombia, Montaño las retoma diaspóricamente: "Son tantas sangres, pero todas tributarias una sola. Se renueva el sentido comunitario en las Américas y contiene eso de que la injusticia con el otro común en cualquier país del continente también la recibo como propia y contra mí" (2020b).

De manera que, Juan Montaño recoge el nombre de George Floyd, Jr. y lo resignifica, lo contextualiza, lo valora como propio porque ve su propia imagen, su propio reflejo en ese nombre que anuncia dolorosa y fatídicamente el potencial de que aquellos 8 minutos 46 segundos también serán los últimos del mismo Juan Montaño en alguna esquina de Mandela's Country. Pero, Montaño sabe - y vale la repetición- que "It's not as simple as talkin' jive, just to stay alive". El jazzman comprende visceralmente el poder de la palabra y del acto de (re)significarla, precisamente porque el poder permea los significados y estos son una fuente mayor del poder social. En efecto, luchar por el derecho a significar resulta central para la (re)estructuración del mundo social y físico en que vivimos (Escobar 2008, 14).

No debemos pasar por alto lo que Montaño escribió pocas semanas después de haber escuchado por primera vez el nombre de George Floyd, Jr., después de haber (re)vivido los 8 minutos 46 segundos que captan toda la historia afrodiaspórica de las Américas. Los nombres, pues, sí importan: 
Defendemos nombres, aquellos que nos son necesarios, por resguardo simbólico de lo épico libertario, por el largo momento creativo o por el tiempo impostergable de la reconstrucción social. El nombre tiene fuerte contenido político y a la vez es corriente cultural. [...] Los nombres para la diáspora afrodescendiente amplían el límite del origen nacional al internacionalismo cimarrón. Si nombramos a Malcolm X, Manuel Zapata Olivella, Marielle Franco o Juan García Salazar más que sus biografías nos acercan sus conexiones con nuestro factor de resistencia política, cultural y comunitaria. Es la lumbre permanente en la proa del bongo de nuestra Historia. (2020b)

Y a fondo de este soneo de Montaño, con acompañamiento de otros soneros que también le cantan a George Floyd, Jr. se escucha la voz/llanto/ grito de Frantz Fanon tarareando que "el racismo no se esclerotiza" (en Montaño 2020d). "I can't breathe”, "I can’t breathe”, "I can’t breathe".

$\mathrm{Al}$ contemplar aquella imagen de la rodilla del policía que aplastaba el cuello de George Floyd, Jr. en pleno día, Juan Montaño no deja lugar a dudas de su significado histórico ya que desentierra los esqueletos de tantas víctimas (y victimarios/as) de la misma rodilla, aunque la forma de esta cambia y fluye según las circunstancias: rodillas, látigos, sogas, armas, cadenas, fuego y un largo y angustioso etcétera. ¿Habría estado escuchando el jazzman a Billie Holiday, la Dama de los Blues, cantar "Strange Fruit" grabado en 1939 mientras procesaba internamente los horrores que su sangre/familia/raza/él sigue sufriendo? Escuchemos con Juan:

Southern trees bear a strange fruit

Blood on the leaves and blood at the root

Black bodies swinging in the Southern breeze

Strange fruit hanging from the poplar trees.
(De los árboles sureños nacen frutos extraños) (Hay sangre en las hojas y sangre en las raíces) (Cuerpos negros que se mecen en la brisa del Sur) (Frutos extraños colgados de los álamos). ${ }^{6}$

El esperpento tal vez mayor de los efectos nocivos del racismo sistémico tan patente en "Strange Fruit" y en los 8 minutos 46 segundos

6. Esta canción fue escrita originalmente en 1937 por Abel Meeropol, en plena época infame de Jim Crow de EE. UU. 
que nos obligan a confrontar a nuestros esqueletos pasados y presentes, sin embargo, subsiste hasta en el aire que respiramos ("I can't breathe", "I can't breathe", "I can't breathe") como Montaño advierte no tan metafóricamente:

El racismo se mide en baja escolaridad, mala calidad de la educación, programas de salud de lástima y el desempleo es la subida vertical de la desesperación. [...] Es la política como se la entiende por estos meses, es un acuerdo entre plantadores del norte centro y sur, para que las barracas jamás dejen de serlo. (2020b)

¡Ay, "las reverberaciones" de aquellos primeros llantos atorados que Glissant lamentaba! (5).

Montaño ha sido categórico en lo que respecta a la ubicuidad de esa implacable plaga que no nos suelta y, por lo tanto, el jazzman asume esos 8 minutos 46 segundos como suyos; no hay cómo desconocerlos o despersonalizarlos. Atento siempre a otras voces y a otros sones, él continúa su jam session así: "Parafraseando la juventud territorial urbana: ¡lo que es con aquellos es con nosotros! O aquello que es con las vidas negras de allá también es con nuestras. [...]. Las opresiones son transseccionales, por eso 'tu problema es mi problema' y 'tu bandera muy bien podría ser la mía'. Si no se entienden los camajanes del Estado-plantación triunfa” (2020d).

No estará de más recordar aquí un informe preparado por el Banco Mundial (2018) en que se lee: "Hasta hace un par de décadas los afrodescendientes no se incluían de forma regular en las estadísticas de la mayoría de los países, por lo que buena parte de sus situaciones y necesidades se desconocían o eran ignoradas" (Freire et al. 2018, 14). ¿No será que "I can't breathe" ha de escucharse como un grito en clave de "I am here", "I exist", "I am Somebody"? Nina Friedemann, la importante antropóloga de Colombia observaba que "Hoy como ayer el desafío de los grupos negros es sobrevivir. La hazaña increíble es que para lograrlo han inventado no solo nueva poesía, danza, música y teatro, sino diversos modos culturales y sociales" (en Lozano Lerma 2016, 194). De nuevo, la voz de Nina Simone vibra dentro de nosotros con su "It's not as simple as talkin' jive, just to stay alive".

Juan Montaño, jazzman/sonero/activista, nunca ha vacilado al asumir enérgica, lúcida y creativamente ese desafío de sobrevivir que Friedemann y Simone destacan. No en vano enseñaba Juan García Salazar que 
"Si algo queremos recuperar de la esclavitud, sin duda, es la resistencia" (Lozano Lerma 2017, 278).

Sean los que sean aquellos "diversos modos culturales y sociales" mencionados por Friedemann, todo apunta a esa misma resistencia como ya he repetido varias veces. Además, en esa apuesta por resistir para no solo sobrevivir, sino también por (re)existir, se encuentra la coherencia y la sincronía de una suerte de pedagogía insurgente que fluye por las sangres y voces afrodiaspóricas. Así leo y escucho el son de los 8 minutos 46 segundos de Juan Montaño, el mismo que teje y entreteje sus soneos con los de otros soneros como Frantz Fanon, por ejemplo. "El antirracismo es lírica combativa, cantada y necesaria; pero también debe comprender mejor la genealogía de aquellos que enfrenta”, advierte Montaño primero y luego su referencia a Fanon que puntualizó en 1956 que 'El racismo, lo hemos visto, no es más que un elemento de un conjunto más vasto: el de la opresión sistemática de un pueblo'" (Montaño Escobar 2020d).

Hay los que quisieran neutralizar y silenciar las voces cimarronas de Montaño y de muchos otros soneros al emplear sus propios "diversos modos culturales y sociales" de autodefensa y negación, pero al jazzman no se le escapa nunca la claridad de la memoria colectiva afro. Por eso, su respuesta a esos atentados contra la humanidad de los afrodescendientes retumba con un tam-tam de alerta: "Unas sofisticaciones mediáticas convierten lo evidente en retahílas analíticas. Pero los asesinatos de personas negras son reales, trágicamente reales, en Estados Unidos, Brasil y Colombia. También en Ecuador y Honduras, aunque con baja noticiosidad" (2020b). Y para que sus lectores/escuchas no se confundan de clave, Montaño afina su soneo repiqueteando con lo siguiente:

en Ecuador, el racismo no solo está en las instituciones del Estado que no garantizan los derechos consagrados en la Constitución, el racismo está en cada rincón: en la televisión, en la palabra, en el deporte, en los chistes, en la vida cotidiana. El racismo está presente cuando no puedes caminar en tu ciudad o en tu barrio sin ser visto como sospechoso o sospechosa; está cuando puedes ser atacado, golpeado y humillado sin que nadie haga nada; o incluso puedes ser asesinado, asesinada; todo esto solamente por el color de tu piel. (2020b)

Y de nuevo el ensordecedor llanto estalla: "I can't breathe", “I can't breathe", "I can't breathe". 
El jazzman es un artesano de la palabra porque comprende que la palabra es poder y, sobre todo, sabe que la palabra ya está suelta (véase Padilla y Montaño Escobar 2018). En otras ocasiones he comentado las tensiones entre el lenguaje del poder y el poder del lenguaje (Handelsman, "Literatura e interculturalidad ..."), y Juan Montaño se ha comprometido a (re)componer su son de 8 minutos 46 segundos con la palabra suelta, con aquella semilla de las voces ancestrales que hace mucho esperan liberarse definitivamente de aquel "libro de cuentas con sus precios" que Glissant había denunciado cimarronamente. Vale recordar al Abuelo Zenón que enseñaba:

En estos tiempos donde se nos habla mucho de lo que no somos y poco de lo que somos, resulta vital mantener viva la palabra de los mayores, como referente de lo que fuimos, como guía para reflexionar lo que somos ahora y como apoyo para construir lo que necesitamos ser mañana. (Ortiz Prado 2018, 54)

Pero la lucha por recuperar esa palabra de los ancestros resulta dura al tomar en cuenta las estructuras tradicionales del poder colonial que reconocen una sola gramática, la misma que sigue asfixiando a todas aquellas que amenazan con "descolonizar la mente y desalienar la palabra alienadora y volver a la palabra viva, recrear el lenguaje, el pensamiento y la rebeldía para rescatar valores perdidos y espirituales”, según planteaba Manuel Zapata Olivella (en Cariño et al. 2017, 529). En efecto, Zapata Olivella siempre había insistido en la centralidad de la palabra como recurso de poder, un poder que se tenía que conquistar en el camino a la liberación, tanto corporal como epistémica. ${ }^{7}$

Por su parte, Montaño ha constatado que "cada abuelo y abuela fueron (aun lo son) la biblioteca que los Estados olvidaron destruir [...]" (2018a, 104). Por eso, aquellos primeros llantos atorados que se escuchaban desde las entrañas de los barcos negreros no hemos de tomar como señal de impotencia. Todo lo contrario puesto que son los primeros testimonios de un cimarronaje naciente e inagotable que en su conjunto sirven

7. Para una mayor elaboración de este tema, véase el capítulo VI ("Territorios y guardianes de la memoria colectiva: Lecciones aprendidas de Juan García Salazar, Antonio Preciado Bedoya y Juan Montaño Escobar") de mi libro Representaciones de lo afro y su recepción en Ecuador. Encuentros y desencuentros en tensión (Handelsman 2019, 187-214). 
de "[...] guardiana del secreto/del mar y nuestras propias singladuras,/de nuestras propias brújulas,/de nuestro propio rumbo/de nuestros propios remos", según ha cantado el poeta Antonio Preciado (2006, 244-7). ${ }^{8}$

No es una casualidad que Pierre Bourdieu haya comentado que "there are no neutral words"; es decir, no hay palabras inocentes (1991, 40). Juan Montaño conoce esa realidad y la siente visceralmente, situándola en pleno centro de las luchas de resistencia de la actualidad. Al ponderar nuestros tiempos convulsionados a los cuales responden los movimientos de Black Lives Matter de muchos países, el jazzman suena su protesta: "Bonita paradoja para derrotar el olvido y la ceguera cotidianos: Black Lives Matter. La plantación responde con desdoro: White Lives Matter" (2020c).

En efecto, las palabras marcan toda una historia de luchas por controlarlas o por liberarse de ellas y de sus múltiples significados. De ahí, Montaño no deja lugar a dudas al advertir a sus lectores/escuchas: "Negro fue el calificativo sistémico para enunciar el racismo contra las personas africanas. Aunque el cimarronismo cultural le ha dado la vuelta efectiva, los grupos racistas, según el interés de opresión política, nos disputan el significante (el conjunto ideológico de la representación) y el significado (el simbolismo del significante). ¿Por cuánto tiempo se desconcertaron con el black is beautiful?" (2020c).

No nos equivoquemos, sin embargo, en el fondo Montaño comprende que apropiarse de la palabra es un acto decolonial y epistémico, el mismo que le permitirá contar y resignificar las historias ausentes de los registros oficiales del poder. En este sentido, Edizon León ha puntualizado que "el cimarronaje no es únicamente una forma de devolverse, tomarse o construir la libertad, sino es un hecho de 'volverse' humanos, de darse humanidad, de volver a ser Seres existentes, visibles” $(2015,213)$.

En el contexto específico de Black Lives Matter, los últimos $8 \mathrm{mi}$ nutos 46 segundos de vida de George Floyd, Jr. esperan las palabras que los llenarán de sus propios contenidos para, así, completarlos de significados de casa adentro. No creo exagerar al insistir que toda la obra de Juan Montaño es un continuo y permanente son de estos mismos 8 minutos 46 segundos que a través de toda la historia afrodiaspórica representan una

8. Estos versos vienen del poema que Preciado tituló "Poema para ser analizado con carbono 14" que se encuentra en Antología personal. 
suerte de ausencia producida por los inacabables crímenes de lesa humanidad. "Así se compone un son" diría el jazzman, ${ }^{9}$ un son que da voz a todo un proceso de "reconocer, reafirmar y poner en vigencia las identidades, [...] entendido como un espacio para recuperar la palabra y hablar de nosotros mismos, con nuestras propias voces sobre lo que somos, dejando de lado lo que los otros dicen [o no dicen] que somos" (García Salazar y Walsh 2017, 98).

\section{UN NUEVO SONEO PARA SEMBRAR MEMORIAS ANCESTRALES: DESAPRENDER PARA (RE)APRENDER}

Pero el son de Juan Montaño no termina todavía, ni tampoco mi intento de acompañarlo con este modesto soneo mío. En un artículo que Montaño publicó en El Telégrafo de Guayaquil en 2017 titulado "La negritud del siglo XXI", él proponía que "La continuidad de nuestras acciones por la plenitud de derechos no dependerá de novedades académicas o la aceptación política de las organizaciones progresistas de nuestras reflexiones críticas, para nada, 'el largo de la pisada' será consecuencia de cuanto produzca la siembra de pensamientos". ${ }^{10}$ En el caso particular de Juan Montaño, esa "siembra de pensamientos" no se acaba con sus escritos de opinión o sus publicaciones periodísticas, una muestra de la cual he tratado de resaltar en estas páginas por su lucidez y constancia, y por su capacidad de entretejer historias, vivencias y saberes simultáneamente símiles y disímiles según la mejor tradición afrodiaspórica de la araña Ananse. ${ }^{11}$ De hecho, ese tejido de reflexiones y representaciones comprendido como un corpus identitario desde y a través de la palabra suelta, y con miras siempre hacia la (re)existencia, tal vez llegue a su plenitud con sus obras de ficción,

9. Las dos colecciones de cuentos escritas por Montaño se titulan Así se compone un son $(1999,2008)$. Retomaré este tema más adelante en este ensayo.

10. Este artículo fue publicado el 22 de abril de 2017 en la página de "Opiniones" de El Telégrafo, en la que Montaño tenía una columna semanal.

11. Entre las muchas acepciones de la araña Ananse, cuyo origen viene de los Ashanti, me refiero a su poder simbólico que llegó a las Américas con los primeros esclavos y que veían en la araña sabiduría, creatividad y la capacidad de engañar a los opresores. Además, el tejido que Ananse hilvana a lo ancho y a lo largo de las Américas representa unidad y solidaridad entre los afrodescendientes. 
un género literario que el jazzman practica pero que muchas veces pasa por inadvertido entre el público lector. ${ }^{12}$

Hasta la fecha, Montaño ha publicado dos volúmenes de cuentos y una novela que él ha caracterizado como un "Thriller (afro)ecuatoriano". ${ }^{13}$ Aunque no pretendo aquí hacer un análisis de estas tres publicaciones propiamente, sí voy a enfocarme en uno de los cuentos del segundo volumen de Asi se compone un son y, más adelante, ofreceré unas reflexiones acerca de la novela. ${ }^{14}$ En ambos casos, pienso destacar cómo Juan Montaño concibe y escribe su ficción para complementar y completar mi lectura de su son de los 8 minutos 46 segundos.

Recordemos que los cimarrones a través de la historia luchan por su humanidad, es decir por su derecho a existir y a ser, como Edizon León ha propuesto y a quien cité en líneas anteriores. Sin duda alguna, Juan Montaño es un cimarrón precisamente porque desde hace mucho tiempo ha utilizado la palabra escrita como su arma de combate al defender esa humanidad. Juan García Salazar enseñaba que "transmitir lo aprendido por medio de la palabra es parte de nuestra tradición cultural de nuestro pueblo, así lo ordenan los mandatos ancestrales. La palabra es la herramienta más segura para trasmitir lo que se guarda en la memoria colectiva de los pueblos y nacionalidades, a los que les fue negado el derecho a la letra" (García Salazar y Walsh 2017, 24). Y lo que se guarda en la memoria colectiva, y lo que resuena desde la escritura de Juan Montaño es que Black Lives Matter.

12. Aunque un análisis de las múltiples razones por el desconocimiento general de la narrativa de Montaño rebasa los propósitos inmediatos de este ensayo, me limitaré a señalar que la falta de un sistema efectivo de distribución y marketing por las editoriales consta como un obstáculo mayor, el mismo que afecta negativamente a muchxs escritores del Ecuador. Además, me atrevería a sugerir que un impedimento adicional, en el caso de la ficción del jazzman, será una equivocada noción de que él es un escritor relevante principalmente para lectores afro.

13. Véanse: Así se compone un son, vol. 1; Así se compone un son, vol. 2; El bisnieto cimarrón de F. Dzerzhinsky. Thriller (afro)ecuatoriano.

14. Para leer algunos estudios míos más elaborados de varios cuentos y la novela de Montaño, véanse: Leyendo la globalización desde la mitad del mundo. Identidad y resistencias en el Ecuador (2005, 69-111); Representaciones de lo afro y su recepción en Ecuador. Encuentros y desencuentros en tensión (2019, 63-94; 187-214); "El bisnieto cimarrón de F. Dzerzhinsky. Thriller (afro)ecuatoriano, una novela de Juan Montaño Escobar", Kipus: Revista Andina de Letras y Estudios Culturales, 47 (enero-junio 2020): 139-43. 
En lo que respecta específicamente a su ficción, el jazzman complejiza esa humanidad al máximo, superando rancios exotismos y estereotipos que siguen deshumanizando a los afrodescendientes. El investigador, Javier Eduardo Pabón, acierta al puntualizar que Montaño "recupera las voces de los protagonistas de la historia y las actualiza con una nueva voz propia" (inédito: 122). ${ }^{15}$ Como se verá a continuación, esa recuperación y actualización de voces emerge con fuerza en el cuento titulado "El último carajo del general” (Montaño Escobar 2008, 181-201).

Frente a una historia oficial que con demasiada frecuencia ha minimizado o distorsionado — cuando no ha borrado por completo- el protagonismo (es decir, las voces) de muchos afrodescendientes, Montaño recurre a la ficción donde la imaginación abre posibilidades otras de reflexión y representación. Su propósito como escritor cimarrón está claro: "Si no existe [el protagonismo] o no está próximo a existir, entonces lo reinventamos" (2018b). ${ }^{16}$ No estará de más repetir aquí con Juan García Salazar que "los pueblos de origen africano tuvieron que reconstruir su identidad y cultura a partir del dolor de la dispersión y deshumanización" (García Salazar y Walsh 2017, 84-5).

Stuart Hall enseñó hace tiempo que "los sujetos de lo local, del margen, solo pueden entrar en la representación [...] recuperando sus propias historias ocultas. Tienen que procurar narrar, nuevamente, la historia, pero esta vez de atrás para adelante". Luego, Hall continuó insistiendo que no se puede

describir los momentos de nacionalismo colonial olvidando el momento en el cual los sin voz descubrieron que, efectivamente, tenían una historia que contar, que tenían lenguajes que no eran las lenguas del amo, ni las lenguas de la tribu. Se trata [...] de un momento enorme. El mundo comienza, en ese mismo momento, a descolonizarse. $(2013,530)$

15. He tomado esta cita del manuscrito original (p. 122) del nuevo libro de Pabón que pronto será publicado por la editorial Abya-Yala de Quito con el título, A tres voces: poesía, tradición oral y pensamiento crítico de la diáspora en el Ecuador.

16. Para los escépticos que quisieran deslegitimar la creación de Montaño de "nuevos sentidos acerca de la condición afro" por haber recurrido a la ficción e imaginación, Stuart Hall ha anotado que "la identidad cambia de acuerdo a la forma en que la pensamos, escuchamos y experimentamos" $(2013,423)$. La referencia aquí a "los nuevos sentidos acerca de la condición afro" viene de Gustavo Abad (2013). 
Yo añadiría a esta reflexión de Hall lo que Juan García señalaba (y que cité previamente): "Para los mayores, la historia arranca en el momento en que empezamos a ser personas" (Viveros 2018, 29-30).

En efecto, "El último carajo del general" ejemplifica la medida en que Montaño se ha comprometido a contar historias y devolverles a sus personajes la condición de ser personas, algo que George Floyd, Jr. - junto con todas y todos los George Floyd habidos y por haber- no alcanzó a probar a plenitud. El cuento se basa en la historia del general Eloy Alfaro y la Revolución Liberal que él lideró en 1895, fecha en que nació el Ecuador moderno. El acierto del cuento, sin embargo, radica en la manera en que Montaño (re)inserta a los afrodescendientes en la historia nacional como protagonistas o, si se prefiere - y para seguir el ritmo del tam-tam de este ensayo/soneo- la manera en que les devuelve aquellos 8 minutos 46 segundos borrados de muchas historias, cuando no de todas.

Recurrir a la historia para completar la misma desde la ficción corresponde perfectamente al proyecto pedagógico y cimarrón de Montaño. En primer lugar, él sabe que "Ser negro o negra no es un dato de la biología sino de la historia” (Lozano Lerma 2016, 210). En cuanto a la historia nacional en concreto, el jazzman seguramente ha escuchado a su mentor, Juan García Salazar, el mismo que ha puntualizado en 1989 en su tesis de master en Historia de la Johns Hopkins University: "El absoluto desconocimiento que la historia oficial muestra sobre los negros y las negras ecuatorianas/os sumada a la negación de su papel en la historia nacional [...] ha hecho de los propios negros/as o afro-ecuatorianos/as elementos extraños a ellos mismos y ellas mismas" $(2020,30)$.

Frente a ese desconocimiento general de la amplia participación de los negros durante la época alfarista y la lucha de las fuerzas del liberalismo "que se prolongará a lo largo de treinta y tres años desde su fase insurgente (1883-1912) hasta la derrota de la Revolución de Concha (1913-1916)" (Sylva Charvet 2010, 78), Montaño inicia su cuento en los últimos momentos de vida de Alfaro, mientras escuchaba los gritos de una multitud alocada que se preparaba para sacarlo de la prisión y arrastrarlo por las calles de Quito antes de matarlo salvajemente en 1912. Además de aquellos gritos, lo que más le inquietaba a Alfaro en estos últimos momentos fatídicos fue una voz que sonaba desde su memoria como presagio: "Algún día, general el único dolor que sentirá será el causado por el mal recuerdo 
de quienes realmente le apreciaron y por su promesa incumplida" (2008, 181).

Lo genial del cuento es que todo gira en torno al momento mismo, en octubre de 1882, cuando Silverio Macondes, un campesino afro de la provincia de Esmeraldas, el que tres veces se había negado a unirse al general Alfaro y que finalmente aceptó, pero bajo una sola condición: "Mi pedido coronel José Eloy Alfaro, es que cuando triunfes se terminen los padecimientos de los conciertos, mis parientes, en toda la República. Además, tu Gobierno les dará un pago por el trabajo que nunca dejaron de cumplir con honrosa puntualidad y talento como si la obra fuera de ellos y no ajena. Así los parientes se irán a vivir adonde quieran” (194-5).

$\mathrm{Al}$ aceptarle el pedido mientras decía que "Te daré por escrito lo que hemos acordado", Silverio Macondes respondió contundentemente:

A la mierda los papelitos, coronel. Escuché tu palabra, la entendí. Muy bien la entendí, se guardó en mi memoria y en la de los Ancestros. Eso es lo más sagrado que acarrearás contigo coronel José Eloy Alfaro, por ahora con sosiego. Pero ni muerto podrás soportar el dolor de la palabra incumplida. Ni muerto encontrarás paz, si perviertes el color de tu palabra. (195)

Con una estructura narrativa y temporal de zigzagueo, parecida a un son cuyos soneos entran y salen intermitentemente, Montaño reconstruye un episodio de la historia nacional, pero esta vez desde una memoria ancestral que no se olvida de aquella promesa incumplida. De hecho, es a partir de esa memoria que Montaño logra devolverle a Silverio Macondes su plena humanidad, combinando su valentía de guerrero mambí con una vulnerabilidad arraigada en el vaivén de un sinnúmero de promesas incumplidas responsables por toda una historia de ilusiones y desilusiones, de culpabilidades ajenas y propias. En efecto, esa es la parte de la historia que el jazzman capta incisivamente en "El último carajo del general". Advierte la voz narrativa del cuento: "Ellos eran la guerrilla mandinga que un historiador describió en sus escritos, pero luego arrepentido borró para no endosarle gloria a unos negros venidos de no se sabía dónde” (195).

Más que la gloria, lo que le interesa a Montaño como cuentista es restituir en el personaje su condición de ser humano como actor de la historia por una parte y, por otra, inculcar en los lectores una sentida conciencia de dicha humanidad. Silverio Macondes, claro está, es un personaje 
de ficción, pero al mismo tiempo sirve para afrobetizarnos a todos, sensibilizándonos de una cosmovisión que viene de las memorias ancestrales y permea las de hoy. ${ }^{17}$

Silverio es el hijo del liberto Melquíades Macondes, "constructor de naciones y pueblos, guerrero malinké (184), y durante todo el cuento la voz silenciosa del padre liberto lo guía y le reprocha, según las decisiones tomadas y por tomar de Silverio. En la segunda ocasión de haber conversado con Alfaro, este ya proclamado Jefe Supremo y en guerra contra el gobierno de Quito, Silverio "Recordó las veces que su padre esquivó propuestas militares, que otros aceptaron y regresaron lisiados, se quedaron pudriéndose en valles serranos o se ahogaron en algún río costeño" (185). Así que la memoria, por segunda vez, pudo más que las palabras inmediatas del General:

- ¿Por qué no viene con nosotros?

-No es mi guerra. [...]

$-[\ldots]$ ¿Cuál es su patria?

-Mis ancestros que pueblan estas tierras hace siglos, ellos son la auténtica patria. (185)

$\mathrm{Al}$ aceptar finalmente juntar fuerzas con Alfaro después de una importante derrota militar del general en 1882, y a pesar de las advertencias del padre Melquíades, el resultado inmediato de su decisión fue que el gobierno le confiscó a Silverio su finca, y su esposa que estaba encinta "malparió y fue obligada a servir a la familia del gobernador" (187). Inicialmente Silverio estaba dispuesto a aceptar los sacrificios y sus consecuencias porque había confiado en la promesa de Alfaro de terminar definitivamente con el sistema oprobioso del concertaje, el mismo que había reemplazado la esclavización, relegando la abolición de los esclavos de 1822 y la manumisión de 1851 a otras promesas incumplidas. Con el paso de los años y el aumento de muertos entre sus compañeros, el narrador del cuento explica:

17. Para una explicación más detallada de la afrobetización, véase a Javier Eduardo Pabón (inédito, 96-7). 
Veinticinco años cumplidos apenas y ya padecía el agobio de las muertes en combates desiguales de sus amigos, sufría el abandono de la tranquilidad de los buenos motivos para tanta muerte, no podía con el peso de la conciencia por haber desobedecido los consejos del padre. (188)

Silverio Macondes es un personaje/hombre de conciencia, de sentimientos nobles y de una autoestima que provoca admiración entre sus pares; es un hombre pensante que se reconoce en la historia de su pueblo, en la memoria ancestral. También es un cimarrón que se había entregado en cuerpo y alma a la lucha, no a la de Alfaro o del liberalismo exactamente, sino a la de "la libertad sin condiciones para los conciertos" (200).

Después de años de pelear, Silverio se dio cuenta de que era tiempo para retirarse y, en el momento del clímax del cuento, cuando le anuncia a Alfaro su decisión, Silverio le dice: "Me harté de sus coroneles hacendados, pero ya no importa. Pasaba a despedirme y recordarle el pago de su promesa" (200).

En momentos antes de comenzar el retorno a sus respectivas casas, Silverio comunica su decisión a los compañeros, indicándoles: "Voy a comprobar que la palabra del general Eloy Alfaro tiene sello sagrado. Él hizo su promesa ante nuestros Ancestros y sé que tiene serenidad en el alma para no engañarse con los miedos de sus alianzas. A los Ancestros no se les miente" (198). Pero este anuncio junto con su última conversación con Alfaro venía con no poca ansiedad y angustia: "Desde que se estableció el campamento, Silverio Macondes estaba hundido en el sopor de recuerdos que no le correspondían a él, sino a la memoria de su padre que llegaba a visitarlo como a pedirle explicaciones por los muertos sin provecho de esta guerra que había hecho suya" (196). Lamentablemente, Eloy Alfaro no comprendió a Silverio al escucharlo advertir: "Sepa, general, que no temo a ninguna muerte, sino a los sagrados muertos de mi conciencia" (201). ${ }^{18}$

18. No fue hasta que Alfaro gritó su último carajo, momentos antes de ser arrastrado por las calles que entendió que había traicionado a los únicos fieles que habían creído en su palabra, la misma que sacrificó por los intereses creados de ciertos sectores del poder político y económico del país. ¿No será que ese carajazo simboliza un acto de arrepentimiento al reconocer la plena humanidad y lealtad de los conciertos y, al descubrir esta verdad, Alfaro también logró (re)encontrar su propia humanidad, la que le había convencido a Silverio Macondes a confiar en él? En efecto, lo que le interesa a Juan Montaño como creador es humanizar a sus personajes y no venerar 
Después de despedirse del general, "Silverio no volvió la vista hacia atrás. Apenas empezaba la tarea más asqueante de cualquier guerrero: recuperar la fe en sí mismo y aprender a vivir con las malas señales del destino" (201). Así que la verdadera tragedia del cuento no es el asesinato de Eloy Alfaro, sino la deuda que todavía los afrodescendientes esperan cobrar a lo largo y a lo ancho de las Américas. Por eso, "Los muertos resuellan en sus oídos por la paz negada a los parientes conciertos. No solo eran los de estos días, más bien eran generaciones de guerreros que le atestaban la sangre caliente de este momento, que se sintió desolado al ver una estela de cadáveres inútiles hasta el fin del páramo [...]” (197).

Seguramente, Erika Sylva tenía en mente esa deuda al referirse a la paradoja histórica de la provincia de Esmeraldas. Aunque a través de toda la historia del Ecuador, Esmeraldas ha sido cuna de muchas de las primeras luchas libertarias e independentistas (como fue el caso de la Revolución Liberal destacada por Montaño en "El último carajo del general”), Sylva ha anotado que "a inicios del siglo XXI continuaba siendo una de las más postergadas, lo que se transparentaba en la alarmante precariedad y exclusión en la que continuaba viviendo su población negra, también debido al persistente racismo que se registraba aun en la sociedad ecuatoriana $(2008,83)$.

Y con esto, otros muertos lejanos y cercanos resuellan en nuestros oídos de hoy por la paz negada: "I can't breathe", "I can't breathe", "I can't breathe".

\section{SONEO PARA (RE)PENSAR CIMARRONAJES CASA ADENTRO, CASA AFUERA}

Se me ocurre que "El último carajo del general" le ha servido al jazzman como preludio de su revisión de las historias oficiales de la Revolución de Carlos Concha que comenzó en 1913, poco después del asesinato de Eloy Alfaro. Sin entrar yo en detalles sobre dicha revolución, Montaño ha escrito "Cuatro negros pelagatos. Breves capítulos de la Revolución de Esmeraldas" para contrarrestar las nociones generalizadas de las causas de ese conflicto. De la manera más contundente, él insiste que fue en realidad

a héroes deshumanizados debido a su propia mitificación. 
una guerra antiesclavista más que un conflicto entre facciones de liberales, por lo menos en lo que respecta a la participación de los afrodescendientes. ${ }^{19}$ De ahí la pertinencia del cuento de Montaño en el cual puso de relieve la centralidad de la promesa incumplida, el eje en torno al cual toda la historia afro sigue girando.

De acuerdo a la buena, pero dolorosa tradición de Silverio Macondes y su padre Melquíades, al ponderar esa revolución antiesclavista y esmeraldeña (1913-1916), Montaño sembró una espinosa pregunta fundamental: "Cada individuo cimarrón [...] debió preguntarse, con igual o mayor énfasis, el injusto porqué de las haciendas infinitas [...] y a ellos ni el breve espacio para la sepultura" (2019a, 6 julio 2019).

Esta misma injusticia social junto a la referencia a los cimarrones nos conduce a la reciente novela del jazzman, El bisnieto cimarrón de F. Dzerzhinsky, Thriller (afro)ecuatoriano (2019). Juan García ha señalado que "son las nuevas generaciones que están pensando el significado de cimarrón como ser de resistencia. El cimarronaje pasa a ser una herramienta para repensarnos, para usar esta actitud de desobediencia y resistencia en el ahora. Pero eso no implica desligar el acto y actitud de desobediencia y resistencia contemporánea de la historia y de la memoria colectiva" (García Salazar y Walsh 2017, 168).

Brevemente, el argumento de El bisnieto cimarrón de F. Dzerzhinsky nos inserta en el conflicto de las FARC de Colombia, junto a sus inevitables incursiones en el Ecuador durante los últimos años del siglo pasado. ${ }^{20}$ A pesar de ser una novela de ficción, con los referentes reales del texto (es decir, los nombres de ciertos actores de los archiconocidos eventos del conflicto), Montaño reconstruye una historia dolorosa y trágica al contar la vida de Omar Makwassé, un individuo cincuentón que por varias circunstancias de la vida fue incorporado en un mundo de espionajes internacionales. Primero, fue reclutado durante sus días universitarios por unos operativos rusos, y luego, después de unos años de una aburrida

19. Montaño publicó estos "Breves capítulos" en siete entregas de un total de veintiún capítulos en Rebelión-Opiniones y Noticias Rebeldes sobre el Mundo entre el 15 de junio de 2019 y el 13 de julio de 2019. Ver https://www.revolución.org.

20. Para una reseña/propuesta de lectura más amplia, véase Michael Handelsman, "El biznieto cimarrón de F. Dzerzhinsky, Thriller (afro)ecuatoriano, una novela de Juan Montaño Escobar" (2020, 139-43). 
jubilación, de nuevo se dejó convencer que la clandestinidad y una vida de subterfugios y conspiraciones constituían su razón de ser.

Como la novela explica, Makwassé, el espía, fue entrenado y formado en la vieja escuela de Félix Edmundovich Dzerzhinsky, fundador en 1917, por orden de Lenin, de la Comisión Extraordinaria de Toda Rusia para Combatir la Contrarrevolución y el Sabotaje. Conocidos como chequistas, los operativos se distinguieron por su entrega total a una ideología que luchaba por la justicia social y, con un espíritu de ascetas, libres de enredos sentimentales de cualquier naturaleza, vivían incondicionalmente por la deseada revolución definitiva de la humanidad. Producto de esa formación y compromiso social tan visceral, Makwassé es conocido y se conoce como uno de los bisnietos de Félix Dzerzhinsky.

Pero en su segunda vida como espía, Makwassé el chequista original se vio atormentado por las contradicciones de su contemporaneidad; en vez de esa ideología de justicia social como motor de todas sus decisiones y responsabilidades, se encontró con la dolorosa novedad de que el capital había desplazado los principios revolucionarios. Empresas multinacionales como Blackwater, Dyn Corp y General Dynamic habían convertido las justas causas en un simple negocio entre clientes y contratistas de inteligencia. Tal vez por el aburrimiento de la jubilación, quizás por el hechizo de los 250 mil dólares de sueldo, Makwassé se dejó convencer; aceptó ser el gerente operativo de una empresa cuyo cliente era las FARC.

Evidentemente, hay algunos paralelos o coincidencias notables entre Silverio Macondes y Omar Makwassé, el bisnieto cimarrón. Los dos dudan de participar en conflictos aparentemente de otros; ambos ignoran los consejos ancestrales al aceptar intervenir en dichos conflictos; tanto Silverio como Makwassé cargan con el peso de su desobediencia en forma de un sentido de culpabilidad que no deja de atosigarlos. Mientras Silverio tuvo que lidiar con el razonamiento del héroe nacional Eloy Alfaro, Makwassé se dejó convencer por algunos discípulos descarrilados de otro héroe, Félix Edmundovich Dzerzhinsky (1877-1926), un héroe revolucionario bolchevique que fundó y dirigió a los chequistas de la Unión Soviética.

Esas convergencias narrativas me permiten proponer que los dos personajes son iteraciones de una suerte de arquetipo afro que nace con los primeros muntus en las Américas y continúa en la persona de George Floyd, Jr. De nuevo, se patentiza cómo Montaño emplea aquella promesa 
negada y todavía pendiente para hilvanar épocas y experiencias y, al mismo tiempo, combinar la historia y la ficción para recuperar la condición humana de los afrodescendientes. Sin embargo, referirme a un arquetipo no ha de sugerir alguna artificialidad o mitificación del negro en la ficción del jazzman. Todo lo contario; los personajes que llenan las páginas de ficción de Montaño se caracterizan por sus imperfecciones y vulnerabilidades, cualidades que emergen de las contradicciones inherentes a la condición humana.

He de enfatizar, pues, que dichas imperfecciones y vulnerabilidades no han de implicar una estereotipada pasividad o debilidad de carácter, ni tampoco una falta de voluntad de luchar, resistir y (re)existir. Silverio Macondes, por ejemplo, pone de relieve el complejo tejido que constituye a un cimarrón frente a las múltiples fuerzas e influencias con(tra) las cuales tiene que (re)negociar constantemente. Así es el caso también de Omar Makwassé.

Desde el prólogo mismo de la novela, se lee que "Cimarrón es la resistencia cultural y política del liderazgo afroamericano y en la confusión de adversarios, en el caso del personaje principal persevera en la equivocación de aliados y busquedas de triunfos" (3; las itálicas son mías). Esa es la tradición e historia a la que Makwassé pertenece, a esa "confusión de adversarios” y a esa perseverancia "en la equivocación de aliados y búsquedas de triunfos”. Juan García ha comentado al respecto:

el sentimiento de pertenencia se construye a partir de la raíz africana, pero el sentimiento de pertenencia tiene los valores aquí y unas actuaciones aquí y una interacción aquí. El sentimiento de pertenencia es básicamente luchar aquí en esta sociedad donde estamos insertados, pero si bien las raíces africanas son vitales en estos procesos, no son las únicas que alimentan la construcción de este sentimiento de pertenencia. $^{21}$

De manera que la misma lucha interior que se observa en Silverio es la que caracteriza a Omar. Asumir su pertenencia o identidad como afrodescendiente en el ahora (la contemporaneidad), pero sin deprenderse del ayer (la ancestralidad) mientras sigue persiguiendo cimarronamente

21. Citado por Edizon León $(2015,23-4)$ después de una entrevista con el maestro Juan García. 
el cumplimiento de aquella promesa de plena humanización, resume las inmanentes tensiones entre vivir y luchar casa adentro y casa afuera. Lamentablemente, el racismo sistémico junto con el capitalismo salvaje que aun determinan las relaciones sociales de poder en todas partes dificultan, cuando no imposibilitan, el potencial de sintonizar "una relación con los antepasados $[\ldots]$ con unas prácticas culturales y políticas contemporáneas" (León 23-4).

A diferencia de Silverio que esperaba realizar esa sintonización entre casa adentro y casa afuera por medio del liberalismo y, así erradicar de una vez por todas los rastros de la esclavización que todavía marcaban a los afrodescendientes en Ecuador, Makwassé recurrió al internacionalismo soviético para luchar por la justicia social de todos y todas sin priorizar las relaciones de raza. Se suponía que un proyecto así concebido iba a ser incluyente y global. Sin embargo, al entrar en su segunda etapa de chequista, Makwassé descubrió que los bisnietos de Dzerzhinsky se habían extraviado, entregándose a otros intereses que traicionaban la promesa de un mundo más justo. En una conversación con Artemio, uno de sus jefes de operaciones, Makwassé expresa amargamente su decepción e inconformismo:

Ya no hay héroes, solo guerreros canallas peleando por causas inmorales. [...]. Mira, qué mierda, Artemio, arriesgo la vida por una pavada de hijueputas que no me dejaría ni entrar a sus clubes si yo quisiera. Este mundo cambió hacia lo impensable: un capitalismo de ... ¿ ¿de qué? [...] Conclusión: se acabó la elegancia, la caballerosidad y el honor. El viejo Félix estaría asqueado. (73)

Como respuesta, Artemio confiesa: "Soy lo que dejaron setenta años de poder soviético: un amargo producto sin Dios, ni ley ni fe. Un facineroso agobiado por las contradicciones” (75). ¿Cómo navegar ese mundo de casa afuera siendo un bisnieto cimarrón? ¿Habrá salvación y esperanza de no renunciar a los mandatos ancestrales (in)visiblemente latentes en su nombre de origen africano? Un comentario que comparte con otra afrochequista revela que Makwassé no se ha perdido del todo: "Algún día te haré la narración de los ancestros —-medio solemne- están en el frontispicio invisible del hogar que llevo conmigo" (106).

Más que algún superhéroe de un Thriller, de una novela de acción y de intriga, Makwassé emerge como un cimarrón en crisis con su con- 
temporaneidad y, sobre todo, consigo mismo. Consciente de sus propias contradicciones, de sus principios en riesgo, se atormenta con sus dudas, según plantea la voz narrativa de esa "ficción":

Tuvo miedo a ser capturado y morir en una celda después de un milenio. Morir en el crepúsculo final de esta niebla de profesión [...]. Shangó es esperpento manido de dudas. O sea él, confundido por un ser del ayer con Oggum. Si antes no creyó en el sino benéfico de la voluntad adquirida en la familiaridad con los orishas ahora sospecha de un engaño cruel. ¡Maldito, Artremio! (146)

En medio de ese estado de miedo y confusión, Makwassé sueña con uno de sus abuelos ancestrales que aparece mientras él estaba de regreso a San Lorenzo, Esmeraldas, su ciudad natal. Metafóricamente, después de años de ausencia, Makwassé se encuentra casa adentro y la voz del abuelo le asegura que "Estás en tu sitio Makwassé, estás donde debes estar cerca del río [...]" (154). El abuelo andaba con una barra negra de "guayacán pechiche", un tótem seguramente por sus talladuras. "Eran jeroglíficos parecidos a números, letras y seres zoomorfos. Fue cuando habló de su genealogía de tiempos imprecisos, pero aproximados por abundancia de cosechas, fundaciones de aldeas, nacimientos de niños prodigio, terminación de reinados, matrimonios con otros pueblos y guerras. Todo ello estaba tallado en ese trozo de madera indestructible" (154-5).

$\mathrm{Al}$ terminar de contarle a Makwassé la historia de sus orígenes de afrodescendiente, "le extendió el madero" y le explicó que "de todos eres aquel que merece guardar el cuaderno ancestral de nuestro pueblo, en donde está la historia familiar. Eres el único, Omar, bendito seas, hijo" (155). A diferencia de la voz de Melquíades que reprochó a su hijo Silverio por haber desoído sus consejos, demarcando así los límites impermeables entre casa adentro y casa afuera, las palabras del abuelo de Makwassé tuvieron otro propósito.

En efecto, para Makwassé, despertarse del sueño era como un renacer, un reencuentro con casa adentro que no implicaba una ruptura con casa afuera, ni tampoco con las promesas del bisabuelo Félix Dzerzhinsky: "El papá Changó de los chekistas. El fundador de esta nueva raza de samuráis. De guerreros de sombras profundas" (170). Su abuelo afro, su apapa, símbolo de todos los ancestros de sangre, le enseñó que "ahora él guardaría la memoria física de la familia. Un legado que jamás abandona- 
ría" (156). Gracias a ese reencuentro con los orígenes, con casa adentro, a Makwassé "le devolvió la fe en las cosas buenas de este mundo" (157), dejando abierta la posibilidad de la ya mencionada sintonización entre casa adentro y casa afuera.

Juan Montaño, sin embargo, no es un autor de simplezas o de desenredos narrativos inocentemente felices. Tampoco es Makwassé ingenuo, especialmente en vista de su experiencia con sus nuevos compañeros chequistas, los mismos que se han convertido en contratistas, dejando muy atrás las enseñanzas del bisabuelo Dzerzhinsky. Makwassé, en cambio, es un bisnieto cimarrón y, de acuerdo con el pensamiento cimarrón de Stuart Hall - y del jazzman también-, "La identidad no está en el pasado, esperando ser encontrada, sino en el futuro, esperando ser construida" (Hall $2013,430)$.

Lógicamente, esa construcción con miras hacia el futuro será harto compleja, especialmente porque la promesa diferida, la que se evaporó en el último carajo del general Eloy Alfaro, y que fue ahogada durante los últimos 8 minutos 46 segundos de George Floyd, Jr., sigue dolorosamente ausente en nuestros días. Hall ha puntualizado que, según Marx, "estamos siempre inscritos e implicados en las prácticas y las estructuras de la vida de los demás” (348). Será cierto, pero la socióloga colombiana Betty Ruth Lozano Lerma advierte que "Descolonizarse significa un desprendimiento epistémico del conocimiento europeo, pensar la propia historia, pensar la propia liberación pero con categorías propias, no prestadas" $(2016,42)$.

Esta advertencia de Lozano no debe interpretarse como un llamado al aislamiento cultural o como un craso deseo fundamentalista. Más bien se refiere al proceso pedagógico que el maestro Juan García Salazar cultivaba al luchar cimarronamente por una efectiva y liberadora etnoeducación entendida en términos de desaprender para volver a aprender. Juan Montaño, el escritor, activista y pensador ha recogido las enseñanzas de Juan García como un mandato ancestral: "Nuestra tradición enseña que todo hombre o mujer que aprende de la palabra de los y las mayores, recibe al mismo tiempo, el encargo de compartir lo aprendido con las nuevas generaciones" (García Salazar y Walsh 2017, 24). Así es la escritura de Juan Montaño, así piensa y así comprende el sentido cimarrón de Black Lives Matter. 


\section{BLACK LIVES MATTER \\ ES MÁS QUE TALKIN' JIVE}

Es cierto que Omar Makwassé es un personaje de ficción, producto de la imaginación del jazzman. Pero nosotros, los lectores, especialmente los de casa afuera, nos quedaríamos cortos al no comprender que ese legado ancestral que el afrochequista guardaría y que nunca abandonaría es el mismo que el Abuelo Zenón compartía al recordarles a las nuevas generaciones de "volver a ser donde no habíamos sido" (Walsh 2018, 11). Ahí está la clave para saber escuchar el tam-tam que marca el compás de Black Lives Matter y que Juan Montaño ha asumido como una pedagogía ancestral de resistencia y (re)existencia: "Aquellas tres palabras resumen historias, muchas historias, de resistencia en las ciudades de cualquier país de las Américas, en los mediodías despiadados o en los atardeceres del desamparo cuando por fin se entiende que el Estado es un aparato político inservible para la gente negra de este preciso territorio" (Montaño 2020a).

¿Seremos los de casa afuera capaces de cumplir la promesa hasta ahora negada? ¿Hasta cuándo seguiremos tapando los oídos al sonar los llantos y gritos atorados de "I can't breathe", "I can't breathe", "I can't breathe"? Habrá una razón por la cual Juan Montaño terminó su Thriller (afro)ecuatoriano con una pregunta sin respuesta inmediata: “¿Comienza la resurrección, Omar Makwassé”? (214).

Resurrección de quiénes, me pregunto yo. Se me ocurre que la respuesta estará en ese último carajo de Alfaro que en George Floyd, Jr. siguió sonando con sus últimos respiros de "I can't breathe". Es decir, los dos habrán comprendido - el uno desde casa afuera y el otro desde casa adentro- que las respuestas siempre serán parciales y negadas hasta que los de casa afuera asuman la promesa incumplida como una suerte de mandato ancestral para, así, liberarse de una pandemia más letal que la del COVID-19. Me refiero, claro está, al racismo sistémico que es la semilla misma de aquellos "frutos extraños colgados de los álamos", según cantaba Billie Holiday.

Así leo y entiendo a Juan Montaño Escobar, el jazzman de Black Lives Matter y su son de los 8 minutos 46 segundos. A los escépticos de todas partes que quieren relegar Black Lives Matter a una mera consigna de unos/as revoltosos/as que toman las calles para saquear y fomentar el desorden, les diré que Black Lives Matter es más que talkin’ jive. Con 
sus múltiples y simultáneos significados, emerge una pedagogía de (re) existencia que desde hace tiempo los afrodescendientes practican, mientras que muchos de nosotros y nosotras de casa afuera nos engañamos tercamente al insistir que ese tema es solo cosa de negros. Pero, la promesa incumplida es de nosotros/as, y solo nosotros/as podemos cumplirla.

¿Comienza entonces una resurrección? Juan Montaño no supo lo que le pasó a George Floyd, Jr. hasta un día después del crimen. Tal vez su reacción personal, su testimonio si se quiere, nos ayuda a contextualizar y sentipensar mejor la pregunta:

Es insoportable y hay como una rabia consciente, antigua e insoportable. Allá en Minneapolis, Minnesota, una rodilla le estuvo suprimiendo el aire durante ocho minutos hasta que ya no lo necesitó más. Aun no paro de escuchar blues, el volumen bajo, solo para mí, me facilita la repetición continua de A change is gonna come. En la versión de Sam Cooke, Aretha Franklin, Otis Redding y otros. Qué más da. It's been a long long time coming, but I know A change is gonna come, oh yes it will. ¿Será un axé premonitorio? (2020c)

Para esta última pregunta, solo los ancestros sabrán hasta cuándo durarán los 8 minutos 46 segundos: “I can't breathe”, I can't breathe”, "I can't breathe".

\section{Lista de referencias}

Abad, Gustavo. 2013. "Juan García y Juan Montaño: Territorios distintos y narrativas complementarias desde la memoria afrodescendiente". lalineadefuego (13 enero). Revista Chasqui, n. ${ }^{\circ}$ 120. www.ciespal.net/chasqui.

Bourdieu, Pierre. 1991. Language and Symbolic Power. Traducido por Gino Raymond and Mathew Adamson. Editado por John B. Thompson. Cambridge: Polity Press.

Cariño, Carmen, et al. 2017. "Pensar, sentir y hacer pedagogías feministas descoloniales: Diálogos y puntadas". En Pedagogías decoloniales: Prácticas insurgentes de resistir, (re)existir y (re)vivir. Tomo 2. Editado por Catherine Walsh. Quito: Abya-Yala.

Escobar, Arturo. 2008. Territories of Difference, Place, Movements, Life, Redes. Durham: Duke University Press.

Freire, Germán, et al., eds. 2018. Afrodescendientes en Latinoamérica: Hacia un marco de inclusión. Washington D. C.: Banco Internacional de Reconstrucción / Grupo Banco Mundial. 
García Salazar, Juan. 2020. Cimarronaje en el Pacífico Sur, editado por Catherine Walsh. Quito: Abya-Yala.

García Salazar, Juan, y Catherine Walsh. 2017. Pensar sembrando/sembrar pensando con el Abuelo Zenón. Quito: Universidad Simón Bolívar, Sede Ecuador / Abya-Yala.

Glissant, Edouard. Poetics of Relation. 1997. Traducido por Betsy Wing. Ann Arbor: University of Michigan Press.

Hall, Stuart. 2013. Sin garantías. Trayectorias y problemáticas en estudios culturales, compilado por Eduardo Restrepo, Catherine Walsh y Víctor Vich. Quito: Universidad Andina Simón Bolívar, Sede Ecuador / Pontificia Universidad Javeriana-Instituto de Estudios Sociales y Culturales Pensar / Instituto de Estudios Peruanos / Corporación Editora Nacional.

Handelsman, Michael. 2005. Leyendo la globalización desde la mitad del mundo. Identidad y resistencias en el Ecuador. Quito: El Conejo.

- 2019. Representaciones de lo afro y su recepción en Ecuador. Encuentros y desencuentros en tensión. Quito: Universidad Andina Simón Bolívar, Sede Ecuador / Abya-Yala.

—. 2020. "El biznieto cimarrón de F. Dzerzhinsky, Thriller (afro)ecuatoriano, una novela de Juan Montaño Escobar”. Kipus. Revista Andina de Letras y Estudios Culturales, 47: 139-43.

—. Inédito. "Literatura e interculturalidad. Una propuesta para posibles lecturas otras". En Historia de las Literaturas del Ecuador. Vol. 11. Editado por Fernando Balseca y Leonardo Valencia. Quito: Universidad Andina Simón Bolívar, Sede Ecuador / Corporación Editora Nacional.

Kaplan, Erin Aubry. 2020. "Everyone's an Antiracist. Now What?”. New York Times. 6 de julio. www.nytimes.com/column/erin-aubry-kaplan.

León Castro, Edizon. 2015. “Acercamiento crítico al cimarronaje a partir de la teoría política, los estudios culturales y la filosofía de la existencia”. Tesis doctoral, Universidad Andina Simón Bolívar, Sede Ecuador.

Lozano Lerma, Betty Ruth. 2016. "Tejiendo con retazos de memorias negras/ afrocolombianas. Aportes a un feminismo negro decolonial". Tesis doctoral, Universidad Andina Simón Bolívar, Sede Ecuador.

—. 2017. "Pedagogías para la vida, la alegría y la re-existencia. Pedagogías de mujeres negras que curan y vinculan". En Pedagogías decoloniales: Prácticas insurgentes de resistir, (re)existir y revivir. Tomo II. Editado por Catherine Walsh. Quito: Abya-Yala.

Montaño Escobar, Juan. 1999. Así se compone un son. Vol. 1. Quito: Casa de la Cultura Ecuatoriana.

—. 2008. Así se compone un son. Vol. 2. Quito: Ministerio de Cultura de Ecuador.

-. 2018a. "New things in jams". En La palabra está suelta: Homenaje a Juan García Salazar, compilado por Isabel Padilla y Juan Montaño. Quito: Abya-Yala. 
—. 2018b. "T'Challa (Pantera Negra) o el afrocentrismo estético". Rebelión-Opiniones y Noticias Rebeldes sobre el Mundo. 23 de agosto. https://www.rebelión.org.

-.2019a. "Breves capítulos". Rebelión-Opiniones y Noticias Rebeldes sobre el Mundo. 15 de junio-13 de julio. https://www.revolución.org.

—. 2019b. El bisnieto cimarrón de F. Dzerzhinsky. Thriller (afro)ecuatoriano. Esmeraldas: Casa de la Cultura Ecuatoriana, Núcleo de Esmeraldas.

—.2020a. "Color, cultura y conciencia". Rebelión-Opiniones y Noticias Rebeldes sobre el Mundo. 27 de agosto. https://www.rebelión.org.

—.2020b. “¿Las vidas negras importan?”. Ruta Krítica. 27 de julio. https:// www.facebook.com/RutaKritica.

-.2020c. "No puedo respirar". Rebelión-Opiniones y Noticias Rebeldes sobre el Mundo. 1 de junio. https://www.rebelión.org.

—.2020d. "Racismo, un elemento de la opresión sistemática". Rebelión-Opiniones y Noticias Rebeldes sobre el Mundo. 6 de julio. https://www.rebelión.org.

Ortiz Prado, Alexander. 2018. "Lo llaman maestro". En La palabra está suelta: Homenaje a Juan Garcia Salazar, compilado por Isabel Padilla y Juan Montaño. Quito: Abya-Yala.

Pabón, Javier Eduardo. Inédito. A tres voces: poesía, tradición oral y pensamiento crítico de la diáspora en el Ecuador. Quito: Abya-Yala.

Padilla, Isabel, y Juan Montaño, comps. 2018. La palabra está suelta: Homenaje a Juan García Salazar. Quito: Abya-Yala.

Porras, María Elena, et al., eds. 2012. Encuentro internacional de reflexión y participación: Al otro la'o de la raya: Memoria Quito, 12-13 diciembre de 2011: Año Internacional de los Afrodescendientes. Quito: Abya-Yala.

Sylva Charvet, Erika. 2010. Feminidad y masculinidad en la cultura afroecuatoriana. El caso del norte de Esmeraldas. Quito: Abya-Yala / Universidad Politécnica Salesiana.

Velázquez Castro, Marcel. 2012. “'El Negro Santander' de Enrique Gil Gilbert: memorias subalternas de la modernización". Kipus. Revista Andina de Letras, 32 (II semestre): 5-17.

Viveros, Sonia. 2018. "Escuela de vida". En La palabra está suelta: Homenaje a Juan García Salazar, compilado por Isabel Padilla y Juan Montaño. Quito: Abya-Yala.

Walsh, Catherine. 2018. "Introducción". En La palabra está suelta. Homenaje a Juan García Salazar, compilado por Isabel Padilla y Juan Montaño. Quito: Abya-Yala.

Zapata Olivella, Manuel. 1983. Changó, el gran putas. Bogotá: La Oveja Negra. 